\title{
Generalised involuntary limb twitching after ingestion of Mesobuthus martensii Karsch (Quanxie) powder
}

\author{
PK Lam *, TW Wong, YC Chan, Tony WL Mak
}

\begin{abstract}
A B S T R A C T
Mesobuthus martensii Karsch, commonly known as the Chinese scorpion or Manchurian scorpion, has been used in traditional Chinese medicine as Quanxie to treat chronic pain, tetanus, tremors, convulsion, and paralysis for more than a thousand years. We report a case of poisoning after ingestion of a teaspoon of Quanxie powder. The patient presented with chest pain, dizziness, diaphoresis, generalised involuntary limb twitching, and hypertonia around 15 minutes post-ingestion. The patient recovered uneventfully after supportive management. Intravenous diazepam appeared to be effective in alleviating limb twitching. Failure to accurately measure the dose and to boil before consumption may have contributed to his clinical toxicities.
\end{abstract}

Hong Kong Med J 2014;20:552-5

DOI: 10.12809/hkmj134091

\begin{abstract}
PK Lam *, FHKAM (Emergency Medicine), Dip Clin Tox
${ }^{1}$ TW Wong, FRCSEd, FHKAM (Emergency Medicine)

2 YC Chan, FRCSEd, FHKAM (Emergency Medicine)

${ }^{3}$ TWL Mak, FRCPath, FHKAM (Pathology)

1 Department of Accident and Emergency, Pamela Youde Nethersole Eastern Hospital, Chai Wan, Hong Kong

${ }^{2}$ Hong Kong Poison Information Centre, United Christian Hospital, Kwun Tong, Hong Kong

3 Hospital Authority Toxicology Reference Laboratory, Princess Margaret Hospital, Laichikok, Hong Kong
\end{abstract}

* Corresponding author: lampkrex@hotmail.com

\section{Case report}

A 63-year-old man complained of chest pain, dizziness, and generalised tremors 15 minutes after ingestion of a teaspoon of herbal powder with water in September 2012. He had started taking herbal decoctions prescribed by a registered Chinese medicine doctor 1 month ago because of suboptimal pain control of his trigeminal neuralgia with western medicine. He presented around 2 to 3 hours postingestion to our emergency department because of persistent symptoms. He was fully conscious but the limb tremor was so severe that he could barely walk. There was no numbness, headache, or any gastrointestinal (GI) symptom. Apart from trigeminal neuralgia, he also had a history of ischaemic heart disease and hypercholesterolaemia. The medication on-hand included aspirin, famotidine, simvastatin, metoprolol, isosorbide mononitrate, diclofenac, dihydrocodeine, tramadol, and carbamazepine but he denied overdosing of any of those drugs. He had not taken any other herbs, over-the-counter medicines, or other suspicious foods such as coral reef fish and shellfish.

On arrival he was fully conscious with a Glasgow Coma Scale score of $15 / 15$. His vital signs were as follows: blood pressure $126 / 95 \mathrm{~mm} \mathrm{Hg}$, pulse rate 66 beats/min, respiratory rate 18 breaths/min, oxygen saturation by pulse oximetry $\left(\mathrm{SaO}_{2}\right) 99 \%$ on supplemental oxygen $2 \mathrm{~L} / \mathrm{min}$ via a nasal cannula, and tympanic temperature $36.6^{\circ} \mathrm{C}$. He appeared nervous with diaphoresis. Both his pupils were $2 \mathrm{~mm}$ in size and reactive to light. Cranial nerve examination was unremarkable but generalised involuntary limb twitching with hypertonia was evident. The muscle power in his four limbs was 5/5. Hyperreflexia and bilateral upgoing plantar reflexes were noted; there was no ankle clonus. Cardiovascular examination was unremarkable and his chest was clear. No distended urinary bladder or abnormal bowel sounds were noted. Repeated electrocardiograms showed sinus rhythm with normal axis. First-degree heart block was noted but there were no definite ischaemic changes. The QRS duration and the corrected QT interval were $89 \mathrm{~ms}$ and $431 \mathrm{~ms}$, respectively. Chest X-ray revealed marginal cardiomegaly with clear lung field. The spot haemostix level was 6.2 $\mathrm{mmol} / \mathrm{L}$. Other blood tests including a complete blood picture, urea and electrolytes, serum calcium level, liver function tests, troponin-I, and arterial blood gas were essentially unremarkable, except a slightly raised creatine kinase (CK) level of 408 IU/L (reference range, 24-180 IU/L), which was likely due to generalised muscle twitching.

His chest pain decreased after administering $3 \mathrm{mg}$ of intravenous (IV) morphine. Subsequently, his blood pressure dropped to $66 / 48 \mathrm{~mm} \mathrm{Hg}$ but 
responded to fluid challenge with $500 \mathrm{~mL}$ of IV $0.9 \%$ normal saline. Less limb twitching was noted after administering $5 \mathrm{mg}$ of IV diazepam. The provisional diagnosis was suspected Chinese herbal medicine $(\mathrm{CHM})$-related neurotoxicity but at the time of presentation, the formula of the herbal decoction was not available for identifying the culprit. The patient was admitted to the intensive care unit (ICU) for close monitoring in view of the unstable haemodynamic status upon presentation, which may have been the result of $\mathrm{CHM}$ toxicity or hypotensive effect of morphine.

Seven sheets of CHM prescription formula were subsequently traced back by the patient's son 3 hours after admission. The Hong Kong Poison Information Centre was consulted for opinion. Multiple ingredients, including Quanxie (全蝎, Mesobuthus martensii Karsch), were prescribed according to the formula. However, the patient had remained free of side-effects in the previous month when he took the herbal decoctions as instructed. Further questioning revealed that the patient had found his pain control unsatisfactory even after taking the herbal decoctions. After receiving verbal advice from his Chinese medicine doctor, he took a few pieces of scorpion from the herb package and put them into a food blender. He took a teaspoon of the powder directly with water; this was the first time he took the herb in this form and fashion. He developed symptoms soon after ingestion.

The patient's twitching decreased gradually after ICU admission but he remained hypertonic, which warranted administering another dose of IV diazepam $2 \mathrm{mg} 10$ hours after admission. Otherwise, he was fully conscious with a stable haemodynamic status. Computed tomography of the brain was unremarkable. His symptoms gradually resolved and he was discharged from the ICU and transferred to the Emergency Medicine Ward 16 hours after admission. His CK level peaked to $413 \mathrm{IU} / \mathrm{L}$ and normalised on day 2 . He was discharged 36 hours after admission, and was totally asymptomatic on follow-up 5 days later.

The patient's serum and urine samples, together with the unused herbs and herbal powder, were sent to the Hospital Authority Toxicology Reference Laboratory for further analysis. Poisoning due to other toxic herbs, such as aconitine, strychnine, and matrine was ruled out by liquid chromatographymass spectrometry of the leftover herbal powder. However, detection of the toxic peptides of $M$ martensii was not possible as the laboratory was not equipped to test for these toxins. The patient's urine sample revealed the presence of diclofenac, dihydrocodeine, carbamazepine metabolite, salicylic acid and famotidine but these were the usual medications taken by the patient. The serum salicylate level was far below the toxic level. Judging

\section{攝入東亞鉗蝴（全蠍）粉末後全身肢體出現 不自主的抽接 \\ 林沛堅、黃大偉、陳耀祥、麥永禮}

東亞鉗蠍（Mesobuthus martensii），俗稱中國蝎子或滿洲蝎子，於 中國傳統醫藥中稱為「全䖲」, 用作治療慢性疼痛、破傷風、震顫、 抽搐和瘔㾑由來已久。本文報告一宗因攝入全蠍粉後中毒的病例。病 人吞服一茶匙全蠍粉末 15 分鐘後出現胸口痛、頭暈、出汗, 以及全身 肢體出現不自主的抽搐。患者得到支援性治療後順利康復。靜脈地西 泮似乎可以有效地緩解肢體抽搐。本病例中的患者出現臨床毒性, 可 能是因為未能準確地量度服用劑量和食用前未煮沸有關。

from the history and absence of other toxic alkaloids to explain the symptoms, the diagnosis of this case was compatible with neurotoxicity associated with the consumption of $M$ martensii powder, even though it could not be directly confirmed by chemical analysis.

\section{Discussion}

Mesobuthus martensii Karsch (synonym: Buthus martensii Karsch), commonly known as Chinese scorpion or Manchurian scorpion (東亞鉗蝎 or 馬氏鉗蝎), belongs to the Buthidae family, and is widely distributed in China. The whole body of the scorpion has been used in traditional Chinese medicine as Quanxie for more than a thousand years (Fig). It functions through the liver meridian, extinguishing wind, and stopping tremors and convulsion. According to the literature in traditional Chinese medicine, common indications include chronic pain, tetanus, tremors, acute/chronic childhood convulsions, paralysis, cerebral vascular accident, and fire toxic nodules. ${ }^{1}$ Its use is contraindicated during pregnancy and should be avoided in cases of internal wind with blood deficiency. The

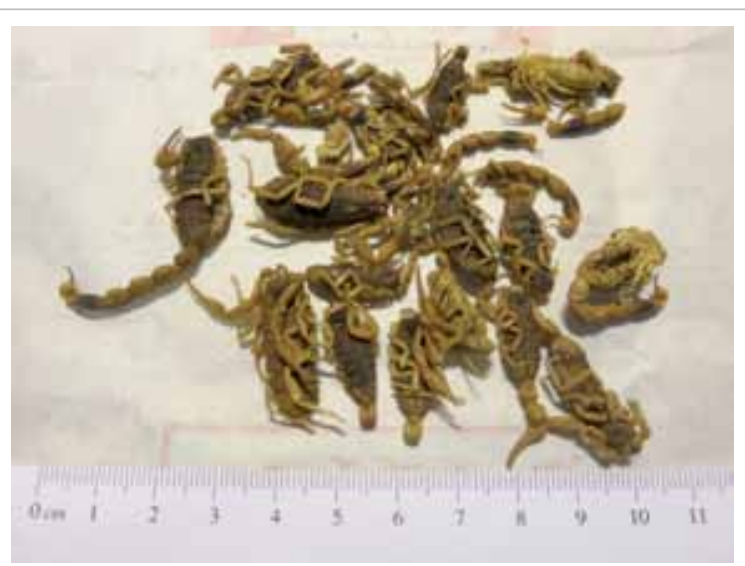

FIG. Quanxie (dried Mesobuthus martensii) 
TABLE. Clinical features of Mesobuthus martensii (Quanxie) poisoning ${ }^{10,13-15}$

\begin{tabular}{|c|c|}
\hline Organ system & Clinical features \\
\hline Central nervous system & $\begin{array}{l}\text { Headache, dizziness, restlessness, limb twitching/spasm, neck stiffness, opisthotonus, salivation, diaphoresis, } \\
\text { confusion, coma }\end{array}$ \\
\hline Cardiovascular system & Palpitation, bradycardia/tachycardia, raised blood pressure followed by collapse in cardiovascular system \\
\hline Respiratory system & Respiratory depression \\
\hline Gastro-intestinal system & Abdominal pain, nausea, vomiting, gastro-intestinal bleeding \\
\hline Renal system & Decrease in urine output, proteinuria \\
\hline Immune system & Anaphylaxis, exfoliative dermatitis \\
\hline Others & Teratogenic effect \\
\hline
\end{tabular}

recommended dose is 3 to $6 \mathrm{~g}$ for herbal decoction ${ }^{2}$ and 0.5 to $1 \mathrm{~g}$ for herbal powder. ${ }^{3}$

The venom of $M$ martensii is complex. At least 51 long-chain peptides related to the sodium $\left(\mathrm{Na}^{+}\right)$channel toxin family and 18 peptides related to the potassium $\left(\mathrm{K}^{+}\right)$channel toxin family have been described ${ }^{4}$ and more have yet to be discovered. Neurotoxins affecting the $\mathrm{Na}^{+}$channel consist of $\alpha$ (highly active in mammalian brain) and $\beta$ (highly active in insects) toxins. Many $\beta$ toxins, which are not noxious to mammals, were found to have analgesic properties in animal models without the risk of dependence. ${ }^{5}$ Recently, a novel peptide, BmK-YA, was found to contain an enkephalin-like sequence and can activate the mammalian $\delta$ opioid receptor. ${ }^{6}$ Novel peptides with antiepileptic (eg BmK AEP), ${ }^{7}$ antitumour (BmK AGAP), ${ }^{8}$ and antibacterial $(\mathrm{BmKn} 2-7)^{9}$ effects in animal models have also been identified in the venom. These findings provide molecular evidence to support its traditional use in Chinese medicine, but relevant clinical studies are still lacking.

Although known to be toxic in traditional Chinese medicine, so far, literature on Quanxie poisoning has been rather limited. Many of the reported cases were due to therapeutic overdose, ${ }^{10}$ which might be related to the way the scorpions are processed. Traditionally, the captured scorpions are put into water for a few hours to allow them to spit out soil from gut, pass retained faeces, and clean the dirt over their bodies. Thereafter they are either boiled with plain water or salt water, resulting in 'plain' Quanxie (淡全蝎) and 'salted' Quanxie (鹽全蝎), respectively. Boiling kills the scorpion and decreases its toxicity. The addition of salt serves to preserve the processed scorpions for prolonged periods. The majority of the processing is undertaken in scorpion farms and there is a lack of standardised protocol. ${ }^{11}$ The details of processing vary from place to place, resulting in variable therapeutic effects, even with the same dose. Moreover, many merchants try to add more salt when processing salted Quanxie to increase its weight, for more profit in sale. The salt content in salted Quanxie could be up to $44.82 \%$ in the market, ${ }^{12}$ resulting in inadequate therapeutic effects with the recommended dose. Therefore, many traditional Chinese medicine doctors may opt to use a higher-than-recommended dose to achieve the targeted effect, thus increasing the risk of clinical toxicities. ${ }^{10}$

In our case, it is difficult to estimate the amount of Quanxie actually consumed as the powder had not been accurately weighed before consumption. With a standard teaspoon, the patient could have taken 5 to $6 \mathrm{~g}$ of the powder, which is higher than the recommended dose. Failure to boil before ingestion might also have contributed to his clinical toxicities.

The clinical features of $M$ martensii (Quanxie) poisoning are summarised in the Table. ${ }^{10,13-15}$ There is no specific antidote, such as anti-venom, for this condition. The mainstay of treatment is supportive. The toxicokinetics of Quanxie have not yet been thoroughly studied. Judging from the rapid onset of clinical symptoms after oral ingestion, we believe that GI absorption is rapid. Gastro-intestinal decontamination with gastric lavage or activated charcoal can be considered if the patient presents within 1 hour of ingestion and has a protected airway. Such a time frame for GI decontamination has also been recommended for other toxic herbs with rapid GI absorption, such as aconitine. Clinicians may choose to consider GI decontamination in patients presenting beyond 1 hour after ingestion but the benefit and risk should be carefully weighed on a case-to-case basis. The benefit would certainly decline with time, which may not justify the risk of aspiration, especially when neurotoxic features such as generalised twitching have already set in, making the administration of activated charcoal further difficult. As Quanxie has not been shown to have enterohepatic circulation or prolonged GI absorption, multi-dose activated charcoal is not recommended. Benzodiazepines appeared effective in alleviating limb twitching muscle spasm in our 
case but its role in the management of $M$ martensii poisoning remains to be elucidated.

\section{Declaration}

No conflicts of interests were declared by authors.

\section{References}

1. Li N, Yu M, Hu LN, Lin J. Collation of animal drugs Quanxie [in Chinese]. Jilin J Tradit Chin Med 2009;29:805-6.

2. Committee of National Pharmacopoeia. Chinese pharmacopoeia [in Chinese]. Vol 1. Beijing: Chemical Industry Press; 2010: 133-4.

3. The editorial committee of "Chinese Herbals", State Administration of Traditional Chinese Medicine. Chinese Materia Medica [in Chinese]. Vol 9. Shanghai: Shanghai Science \& Technology Press; 1999: 129-35.

4. Goudet C, Chi CW, Tytgat J. An overview of toxins and genes from the venom of the Asian scorpion Buthus martensii Karsch. Toxicon 2002;40:1239-58.

5. Shao JH, Zhang R, Ge X, Yang B, Zhang JH. Analgesic peptides in Buthus martensii Karsch: a traditional Chinese animal medicine. Asian J Tradit Med 2007;2:45-50.

6. Zhang Y, Xu J, Wang Z, Zhang X, Liang X, Civelli O. Bmk-YA, an encephalin-like peptide in scorpion venom.
PLoS One 2012;7:e40417.

7. Zhou XH, Yang D, Zhang JH, Liu CM, Lei KJ. Purification and $\mathrm{N}$-terminal partial sequence of anti-epilepsy peptide from venom of the scorpion Buthus martensii Karsch. Biochem J 1989;257:509-17.

8. Liu YF, Zhang ZG, Mao YZ, et al. Production and antitumor efficacy of recombinant Buthus martensii Karsch AGAP. Asian J Tradit Med 2009;4:228-33.

9. Cao L, Dai C, Li Z, et al. Antibacterial activity and mechanism of a scorpion venom peptide derivative in vitro and in vivo. PLoS One 2012;7:e40135.

10. Chang JM. Adverse effects of Quanxie [in Chinese]. J China Pharm 2003;14:484-5.

11. Gao ZJ. Brief review of the processing methods of Quanxie [in Chinese]. J Community Med 2006;4:59-60.

12. Shao XH, Kong XS, Fang LH. Processing of Quanxie and its clinical application [in Chinese]. Lishizhen Med Materia Medica Res 2006;17:232-3.

13. Chen XM. Analysis of adverse effects of Quanxie [in Chinese]. Lishizhen Med Materia Medica Res 2003;14:635.

14. Xiao YC. A case report of neurotoxicity induced by centipede and Quanxie [in Chinese]. China J Chin Materia Medica 1996;21:634.

15. Dai Y. A case report of free decoction for treatment of Quanxie [in Chinese]. J Jilin Med Coll 2009;3:342. 